\title{
filosofias sapatão construções decoloniais a partir do não-lugar
}

\author{
Martina Davidson \\ Universidade Federal do Rio de Janeiro, Brasil \\ martinaadavidson@gmail.com
}

\section{Resumo}

A decolonialidade é a reivindicação/desinvisibilização de um não-lugar criado por processos normativos tidos como inevitáveis e naturalizados. Interpretando a cisheteronorma enquanto instituição e regime, pode-se entender as experiências lésbicas enquanto práticas decolonizadoras. O não-lugar lésbico pode ser interpretado, através de uma leitura de Wittig, a partir das categorias heterossexuais de sexo e/ou gênero e como elas submetem as lésbicas à uma dupla acusação: as lésbicas não são mulheres o suficiente, mas, ao mesmo tempo, não são homens (já que não possuem falo e, portanto, poder). O que pretende este ensaio é fazer, a partir do não-lugar agora lugar, uma tradução que os corpo e existências lésbicas já fazem. Frente à isso, como as sapatão se articulam enquanto existências filosóficas? Uma das respostas possíveis a essa indagação é a de pensar nas existências, no processo de nomear, relacionar, entre tantos, enquanto formas válidas de realização de leituras sobre o mundo real.

\section{Palavras chave}

1| decolonialidade 2| filosofias sapatão $3 \mid$ não-lugar

\section{Cita sugerida}

Davidson, Martina (2021). filosofias sapatão: construções decoloniais a partir do não-lugar. Tramas y Redes, (1), 161-170, 108a. DOI: 10.54871/cl4c108a 
Tramas

\title{
filosofías tortilleras: construcciones decoloniales a partir del no-lugar
}

\begin{abstract}
Resumen
La decolonialidad es la reivindicación/desinvisibilización de un no-lugar creado por procesos normativos considerados inevitables y naturalizados Al interpretar la cisheteronorma como institución y régimen, las experiencias lesbianas pueden entenderse como prácticas descolonizadoras. El no-lugar lesbiano se puede interpretar, a través de una lectura de Wittig, desde las categorías heterosexuales de sexo y/o género y cómo someten a las lesbianas a una doble acusación: las lesbianas no son suficientes mujeres, pero tampoco son hombres (ya que no tienen falo y, por lo tanto, no tienen poder). El propósito de este ensayo es hacer, desde el no-lugar ahora lugar, una traducción que ya hacen los cuerpos y las existencias lesbianas. Ante esto, ¿cómo se articulan las tortilleras como existencias filosóficas? Una de las posibles respuestas es pensar en las existencias, en el proceso de nombrar y de relacionar como formas válidas de realizar lecturas sobre el mundo real.
\end{abstract}

\section{Palabras clave}

1| decolonialidad 2| filosofías tortilleras $3 \mid$ no-lugar

\section{dyke philosophies: decolonial constructions from a place that can't be named}

\begin{abstract}
Decoloniality is the claim of an absent place created by normative processes considered inevitable and naturalized. Interpreting the cis-heteronormativity as an institution and regime, lesbian experiences can be understood as decolonizing practices. The lesbian non-place can be interpreted, through a reading of Wittig, from the heterosexual categories of sex and/or gender and how they subject lesbians to a double accusation: lesbians are not enough women, but at the same time, they are not men (since they have no phallus and therefore no power). The purpose of this essay is to make, from the non-place now place, a translation that lesbian bodies and existences already do. Faced with this, how are the dykes articulated as philosophical existences? One of the possible answers to this question is to think about existences, in the process of naming, relating, among many, as valid ways of carrying out readings about the real world.
\end{abstract}

\section{Keywords}

$1 \mid$ decoloniality $2 \mid$ dykes philosophies $3 \mid$ absent place 


\section{Introdução}

A decolonialidade (falar do Sul para o Sul) trata-se, dentre tanto, da reivindicação/desinvisibilização de um não-lugar criado por processos normativos (Curiel, 2011). Interpretando a cisheteronorma enquanto instituição e regime (Tolentino e Batista, 2019), pode-se entender as experiências lésbicas enquanto práticas decolonizadoras. Isto por que, segundo Curiel (2011), a lesbianidade feminista permite construir autonomias das mulheres perante os homens cisgêneros, tanto no plano sexual quanto nos planos econômicos, emocionais e culturais.

As teorias decoloniais abrem caminho para que sejam geradas novas análises da realidade, provenientes de nossas próprias formas de resistir e viver no mundo. Esse caminho conduz ao resgate de epistemologias que buscam se distanciar da lógica hegemônica dominante derivada dos sistemas coloniais (Tolentino e Batista, 2019), como no caso de perspectivas lésbicas. As lesbianidade são diferentes formas de viver o mundo, configurando-se como um incessante combate às premissas da colonialidade e dos Estados-Nação.

Essas formas de viver não têm origem unicamente no fazer acadêmico, mas nas vivências cotidianas, nas disputas geradas ao se construir relacionamentos, afetividades, solidariedades e autonomias dentro de um mundo globalizado (Preciado, 2019). A partir desse lugar do existir como resistir, propõe-se, neste ensaio, reconfigurar as filosofias sapatão a partir das ruas e militância, superando barreiras coloniais impostas ao SulGlobal e suas dissidências.

\section{filosofias ${ }^{1}$ sapatão}

E o tombo feio quem toma é aquele que não teve a rua para aprender a manha de cair bonito. Nessa hora o sujeito que só sabe subir e olha todo mundo de cima, do conforto de sua liteira política ou filosófica (porque conceito também é cadeira de arruar), pede pra levar rasteira.

(Simas, Rufino e Haddock-Lobo, 2020, p. 13)

\section{O não-lugar lésbico e sua reivindicação}

Se há algo que pode-se deduzir diante da colonialidade enquanto eixo de poder (Santos e Meneses, 2009), é a necessidade da reivindicação dos

\footnotetext{
${ }^{1}$ A utilização de letra minúscula no início da palavra filosofias se dá para contrastar, se opor à Filosofia enquanto algo único, de origem grega.
} 
Tramas

não-lugares criados pela determinação de ideologias, instituições e regimes que ditam, de forma hegemônica aquilo que é tido enquanto normal e ideal (Augé, 1992). Segundo Augé (1992) um não-lugar é um lugar em que não se vive, espaço no qual as pessoas permanecem anônimas, inomináveis e solitárias. Estes não-lugares são habitados por muitas identidades entroncadas ou não, incluindo as múltiplas lesbianidades.

O não-lugar lésbico pode ser interpretado através de uma leitura de Wittig (1980). Segundo a autora (1980), as categorias heterossexuais de sexo e/ou gênero, submetem as lésbicas à uma dupla acusação: as lésbicas não são mulheres o suficiente, mas, ao mesmo tempo, não são homens (já que não possuem falo e, portanto, poder). Com uma orientação sexual original e sem dependência de homens, as lésbicas representam uma grave ameaça à afirmação do determinismo biológico ${ }^{2}$ e da autoridade masculina.

Por isso, a fim de manter o controle dominante sobre as mulheres, a cis-heteronormatividade exclui as lésbicas dessa classe que é caracterizada, pelo patriarcado como detentora de traços de passividade, docilidade e "virtude" (Wittig, 1980). Marginalizadas, ambos pelos homens e pelas mulheres heterossexuais, as lésbicas são exiladas a um espaço além do sexo e do gênero, um não-lugar. Portanto, "uma lésbica tem que ser qualquer outra coisa: uma não-mulher, um não-homem" (Wittig, 2010). Essa dupla alienação força as lésbicas a um vácuo de identidade, uma vez que existe uma recusa em aturar a opressão e as definições impostas pela cis-heteronormatividade (Davidson, 2019).

Como consequência, Lacombe (2013) sugere que os corpos que negam ou resistem à a feminilidade obrigatória - ou que numa leitura wittigiana, lhes é negada tal qual reconstroem suas perfomatividades de gêneroacabam por abrir a possibilidades de novos lugares de encontro identitário que, socialmente invisibilizados e silenciados, são relegados ao não-lugar. A partir de Lacombe (2013) e val flores (2018), encontramo-nos na fertilidade da desheterossexualização de discussões ou âmbitos hegemônicos, tudo a partir dessa negação do caminho reto, por entre curvas sinuosas onde nossas reivindicadas monstruosidades se encontram.

Esse não-lugar passou a ser reivindicado justamente como... um lugar. Um discurso, uma existência válida, um filosofar, um pensar. Aí jaz a travessia da qual fala Preciado (2019). Ele indaga:

O que significa falar para aqueles a quem nos negaram o acesso à razão e ao conhecimento, para aqueles que nos consideraram doentes?

\footnotetext{
${ }^{2}$ Tal determinismo biológico ao qual se refere Wittig, diz respeito àquele que considera que as mulheres são determinadas biologicamente não apenas a se reproduzirem e serem mães, mas também a se relacionarem com homens cisheterossexuais (Wittig, 1980).
} 
Com que voz podemos falar? O jaguar ou o ciborgue nos emprestarão suas vozes? Falar é inventar a linguagem da travessia, projetar a voz em uma viagem interestelar: traduzir nossa diferença na linguagem da norma; enquanto continuamos, em segredo, proliferando um bla-bla-bla insolente que a lei não entende. (Preciado, 2019, p. 24)

O que pretende este ensaio é fazer, a partir do não-lugar agora lugar, através da travessia proposta por Preciado (2019), uma tradução que os corpo e existências lésbicas já fazem. É um convite, não uma imposição, afinal, a Filosofia que impõe de nada deveria interessar a menos que tenha a ver com impor o mínimo sobre justiça e direitos básicos. As epistemologias? Que sejam múltiplas, como as ruas desorganizadas de uma cidade não planejada.

\section{Sapatão também produz filosofias}

As linguagens, corpos e existências sapatão existem enquanto resistências ao que é cisheteronormativo (Lugones, 2014). Entendendo a filosofia enquanto território político (Arendt, 2016) a decolonialidade pode ser um mapa para cortar o tradicionalismo ${ }^{3}$, fazendo assim, com que as estruturas cisheteronormativas se abalem. Existe pretensiosidade neste ensaio, mas esta característica talvez seja necessária quando há anos lésbicas tem sido trancadas em armários. Esta é a hora de falar a partir de vozes lésbicas e do Sul global que durante muito tempo foram silenciadas.

Frente à isso, pergunta-se: como as sapatão se articulam enquanto existências filosóficas? Talvez uma das respostas possíveis a essa indagação seja a de pensar nas existências, no processo de nomear, relacionar, entre tantos, enquanto formas válidas de realização de leituras sobre o mundo real (Cano, 2017). Existe-se enquanto filosofia e as filosofias sapatão existem enquanto Martinas (Luanas, Milenas, Marconis, Angelas, e tantas pessoas mais).

A necessidade de uma autodenominação enquanto lésbica ao filosofar é necessária, pois é nesta ação que se permite a geração de novos sentidos e debates que questionam a matriz cisheteropatriarcal, a hegemonia viril, branca, Norte-globalista (Bezerra, 2013). Assim, a filosofia se torna inerentemente militante, cria-se nas ruas. Isto porque não existe militância acadêmica, por mais que possa existir militância dentro da Academia.

Assim entra "o popular" na filosofia sapatão, que possui linguagem própria, referências próprias, jeitos próprios. Aqui faz-se referência às sapatão que fazem filosofias em mesas de bar, em armários mofados, nas

\footnotetext{
${ }^{3}$ Considera-se aqui o conceito de Edward Burke. Isto é, tradicionalismo enquanto consideração de que "a sociedade é uma criação e não uma construção ou um mecanismo. Sendo uma criação, a sua existência é condicionada por leis naturais." (Duffy; Jacobi, 1993, p. 12).
} 
periferias, onde quer que possam ainda ter seus corações batendo. Afinal, existe uma intenção diária de assassinato da lesbianidade (Peres, Soares e Dias, 2018).

As filosofias sapatão são múltiplas, não podem ser uma Teoria. Não é passível de ser encaixada em um limite, como tampouco pode-se definir ao certo o que é um ou uma sapatão. As filosofias sapatão devem, então, buscar dar conta das multiplicidades sem cair na armadilha acadêmica de querer gerar uma verdade universal (como correntes filosóficas clássicas por muito tempo vêm tentando fazer). Trata-se de criar incertezas - aberturas como a da fechadura do armário que escancara-se ao se nascer lésbica.

Talvez deixar sapatão e mulher como campos conceituais abertos permite repensar filosoficamente, justamente, a dualidade sexo-gênero (Butler, 2008), categorias tão indissociáveis politicamente dentro das lesbianidades academicistas. Reformular categorias que desnaturalizam pactos sociais mesmo dentro da comunidade LGBTI+ ou queer tem a potencialidade de alterar as coisas por dentro, de criar territórios de intervenção política decoloniais (Richard, 2011).

A partir dessas intervenções políticas decoloniais foi possível transcender Safo de Lesbos (por exemplo, tem-se o conceito e ideias de Zami, de Audre Lorde, 2009) mesmo que isto não signifique um abandono de suas contribuições e forjaduras de pensamentos. As filosofias sapatão, feministas interseccionais, feministas negras, entre outras, vão respondendo aos conflitos que aparecem no campo conceitual (Federici, 2017). Nada mais justo, assim se pauta o mundo. Trata-se de criar respostas para problemas que são reais. Afinal, sapatão é carne e osso, não é Sócrates não.

Porém, enquanto a Academia tenta produzir respostas, muitas vezes ignora-se as que já existem na concretude (Corbalán, 2011). Na rua perto de uma ocupação existia um sapatão que trabalhava no comércio. Quiçá nas filosofias sapatão nada possa ser engessado, pois se materializa justamente em campos abertos a serem moldados. No entanto, este ensaio não sugere um abandono de definições: o amorfo vulnerabiliza (Joy, 2010). Todavia, aquilo que se define de cima para baixo talvez desimporte a quem esteja nesse embaixo. Aqui fala-se de como sobreviver. De que semana passada uma lésbica sofreu estupro corretivo. Quem ensinará essa resistência? Safo de Lesbos?

\section{A militância sapatão produz seus próprios conceitos}

A militância tem dialetos e conceituações próprias, taxonomias que permitem pensar questões fundamentais. Primeiro, permite que pensemos os princípios através dos quais as lésbicas são capazes de realizar leituras sobre si próprias, se interpretam, interpelam, nomeiam (Cano, 2017). Os nomes utilizados na militância escondem códigos, normas, valores e ideais que 
condicionam e moldam as possibilidades, limites e formas de possíveis leituras (Ko, 2019).

As categorias com as quais lésbicas se classificam, identificam

e designam podem, no entanto, delimitar parâmetros fixos sobre "o que é ser sapatão" (Nunes, 2018). Sob o guarda-chuva de próprias subcategorias próprias, as lesbianidade podem chegar a delimitar quem é mais ou menos femme, mais ou menos versátil, mais ou menos caminhoneira ou, inclusive, mais ou menos sapatão. A partir do momento em que nomes são criados para habitar o não-lugar lésbico, cria-se nomes que, potencialmente, podem operar como parâmetros normalizadores (Cano, 2017). Se isto se materializa, trata-se de um pensar coercitivo e disciplinante. Onde fica a liberdade múltipla de se ser sapatão?

Nesse sentido, não nos devemos perder nunca da ideia de que as categorias que narramos também nos narram, mas que elas mesmas também nos medem, nos comparam e fazem com que projetemos - em direção a nós e a outras - hierarquias e subordinações (Walker, 1979). Se estabelecermos sapatomêtros, a partir dos quais algumas pessoas seriam mais ou menos sapatão que outras, então as taxonomias criadas para a comunicação passam a funcionar como critérios de pureza e correção. Transformam-se em tecnologias tão normalizadoras quanto aquelas das quais pretende-se escapar.

Por isso as filosofias sapatão devem se preocupar em destituir a tendência, que além de limitante é colonial dada sua importação de países do Norte global, de categorias como golden star (sapatão puras, que nunca transaram com alguém que não reconhecidamente uma mulher). Assim, Halberstam (2008) propõe:

podem existir classificações do desejo, do físico e da subjetividade, com o fim de intervir no processo hegemônico de nomear e definir. As taxonomias imediatas são as que trazemos diariamente pra interpretar nosso mundo e que funcionam tão bem que, em realidade, nem as reconhecemos (Halberstam, 2008, p. 30).

Sem a necessidade de validação por artigos científicos, as filosofias sapatão sabem se definir. Sabem se limitar. Porém, também sabem se deslimitar. Diante disso, propõe-se neste ensaio, talvez como Virginia Cano o faz desde a Academia com suas éticas, que as filosofias sapatão:

a. Tenham jogos de representação sapatão, parâmetros estéticos próprios. Sem que isto seja fechado. Nomes, brincadeiras, jogos - sem ofender, sem tachar.

b. Sejam e falem de sexo e afeto, afinal, a filosofia sempre deveria falar sobre sexo dissidente (Murta, 2006). Significa 
pensar, entre lésbicas as práticas de transar e de amar, estejam elas entrelaçadas ou não. Destruir estereótipos.

c. Se localizem na sociedade, cultura e economia, pensando nas múltiplas condições simbólicas da lesbianidade (Kumpera, 2019).

d. Narrem de modo diferencial, com um sapa-dialeto apresentado ao mundo de formas única e própria. Aqui incluindo as distintas interseccionalidades: sapatonas e negras, e índias, e pobres, e militantes, e do Sul global, e apolíticas, e veganas.

É disto que se tratam as filosofias sapatão. As filosofias se fazem sós. Este ensaio trata-se apenas da tentativa de escrever sobre elas.

\section{Conclusão}

A proposta de filosofias sapatão não é inédita deste ensaio: pesquisadoras diversas têm tensionado categorias de análise e desorganizado a ordem imposta pela colonialidade (Loure, 2007). No entanto, estas palavras somam-se a postura política que pretende visibilizar o não-lugar ocupado por lésbicas devido a colonialidade, em diversos aspectos.

Trata-se, então, de elevar o lugar de subalternidade a um espaço de produção horizontal que busca superar desigualdades ou relações de poder assimétricas (Silveira-Barbosa, 2019). Assim, visando a ruptura com o silêncio e a ressignificação das lesbianidades enquanto filosofias válidas, este ensaio alinha-se com a proposta de Julia Penelope (1990), quando a autora diz: "nós precisamos pensar lésbicamente. Nós precisamos pensar sapatão. Nós precisamos parar de ser complacentes com o nosso próprio apagamento" (Penelope, 1990, p. 104).

Este giro, deslocamento, é um dever político histórico por parte de todos que calaram nossas epistemologias múltiplas. Ademais, para não recair em reedição de hierarquizações e opressões, deve-se incluir análise de lesbianidades a racialização e sua discussão como dever no processo de decolonização (Kumpera, 2019) das filosofias.

\section{Referências}

Arendt, Hannah (2016). Entre o passado e o futuro. São Paulo: Perspectiva. Augé, Marc (1992). On-lieux: introduction à une anthropologie de la surmodernité. Seuil: La Librairie du XX siècle.

Bezerra, Danieli Machado (2013). Tu é entendida, né, doidinha? Simpósio Internacional de Educação Sexual, Maringá. 
Butler, Judith (2008). El género en disputa. El feminismo y la subversión de la identidad. (Traducción Ma. Antonia Muñoz). Barcelona: Paidós.

Cano, Virginia (2017). Ética tortillera: Ensayos en torno al ethós y la lengua de las amantes. Buenos Aires: Madreselva.

Corbolán, Macky (2011). La primera militância es en el lenguaje. Suplemento Tinta China (Buenos Aires), (80).

Curiel, Ochy (2011). El regimen heterosexual y la nación: aportes del lesbianismo feminista a la antropología. Mexico: La Manzana de la Discordia.

Davidson, Martina (2019). Necropolítica lesbocida: uma análise sobre o necrobiopoder, soberania e violências contra lésbicas no contexto bolsonarista. Ítaca (Rio de Janeiro), (34).

Duffy, Bernard e Jacobi, Martin (1993). The politics of rhetoric: Richard $M$. Weaver and the conservative tradition. Santa Bárbara, CA: Greenwood Press.

Federici, Silvia (2017). Calibã e a bruxa: Mulheres, corpo e acumulação primitiva. São Paulo: Elefante.

flores, val (2018). Pedagogías del deseo. Desheterosexualizar el conocimiento o ¿es posible hacer de la danza una experiencia de (des)generización? XI Congreso de Danzas, Educación-Diversidad-Escena, La Plata.

Halberstam, Judith (2008). Masculinidad femenina. Madrid: Egales.

Joy, Melanie (2010). Por qué amamos cachorros, comemos porcos e vestimos vacas: uma introdução ao carnismo, o sistema de crenças que nos faz comer alguns animais e outros não. São Paulo: Cultrix.

Ko, Aph (2019). Racism as zoological witchcraft: A guide to getting out. Herndon: Lantern Publishing \& Media.

Kumpera, Julia Aleksandra Martucci (2019). Lesbianidade e Branquitude. Revista Brasileira de Estudos de Homocultura, 2(4).

Lacombe, Andrea (2013). Dar cuenta de lo indecible. Em val flores y fabi tron (comps.), Chonguitas. Masculinidades de niñas (pp. 195-201). Neuquén: La Mondonga Dark.

Lorde, Audre (2009). Zami, una biomitografía: Una nueva forma de escribir mi nombre. Madrid: La Editora San Cristobal.

Loure, Guacira Lopes (2007). Gênero, sexualidade e educação: das afinidades políticas às tensões teórico-metodológicas. Educação em Revista (Belo Horizonte), (46), 201-218.

Lugones, María (2014). Rumo a um feminismo descolonial. Estudos Feministas (Florianópolis), 22(3), 935-952.

Murta, Claudia (2006). O amor entre filosofia e psicanálise. Revista do Departamento de Psicologia (Niterói, Editora UFF), 18, 57-70. 
Nunes, Hariagi Borba (2018). Sapatão enquanto rizoma: desterritorialização da lésbica. Rio Grande do Norte: Ed. FURG.

Penelope, Julia (1990). The lesbian perspective. Em Jeffner Allner (ed.), Lesbian philosophies and cultures. Albany: SUNY Press.

Peres, Milena Cristina Carneiro; Soares, Suane F. e Dias, Maria Clara (2018). Dossiê sobre lesbocídio no Brasil: de 2014 até 2017. Rio de Janeiro: Livros Ilimitados.

Preciado, Paul Beatriz (2019). Un apartamento en Urano: crónicas del cruce. Barcelona: Anagrama.

Richard, Nelly (2011). Postfacio. Deseos de... ¿Qué es un territorio de intervención política? En AA. VV. Por un feminismo sin mujeres. Fragmentos del Segundo Circuito Disidencia Sexual (pp. 156178). Santiago de Chile: Territorios Sexuales Ediciones/Coordinadora Universitaria por la Disidencia Sexual.

Santos, Boaventura de Sousa e Meneses, Maria Paula (2009). Epistemologias do Sul. Coimbra: Almeidina.

Silveira-Barbosa, Paula (2019). Uma perspectiva sapatão para o estudo do jornalismo. Revista Brasileira de Estudos de Homocultura, 2(4).

Simas, Luiz Antônio; Rufino, Luiz e Haddock-Lobo, Rafael (2020). Arruaças: uma filosofia popular brasileira. Rio de Janeiro: Bazar do Bom Tempo.

Tolentino, Julia Gonçalves e Batista, Nicole Faria (2017). Gênero, sexualidade e decolonialidade: reflexões a partir de uma perspectiva lésbica. Revista Três Pontos (Minas Gerais), 14(1), Dossiê “Diálogos entre antropologia e arqueologia: contribuições e desafios".

Walker, Alice (1979). Coming apart. Em You can't keep a good woman down. San Diego: Harvest.

Wittig, Monique (2010). One is not born a woman. Em Vincent B. Leitch (ed.), The Norton anthology of theory and criticism. New York: W. W. Norton \& Company.

Wittig, Monique (1980). The straight mind and other essays. New York: Harvester/Wheatsheaf. 